\title{
Effect of response format for clinical vignettes on reporting quality of physician practice
}

\author{
Thao Pham*1, Carine Roy ${ }^{2}$, Xavier Mariette ${ }^{3}$, Fréderic Lioté ${ }^{4}$, Pierre Durieux ${ }^{5}$ \\ and Philippe Ravaud ${ }^{2}$
}

\begin{abstract}
Address: ${ }^{1}$ Department of Rheumatology, CHU Conception, 13005 Marseille, France, ${ }^{2}$ Department of Epidemiology, biostatistics and clinical research, CHU Bichat, 13018 Paris, France, ${ }^{3}$ Department of Rheumatology, CHU Bicêtre, Le Kremlin-Bicêtre, France, ${ }^{4}$ Department of Rheumatology, CHU Lariboisière, 75 Paris, France and ${ }^{5}$ Department of public health and medical informatics, Hôpital Européen Georges Pompidou and Paris Descartes University, Paris, France

Email: Thao Pham* - thao.pham@ap-hm.fr; Carine Roy - carine.roy@bch.aphp.fr; Xavier Mariette - xavier.mariette@bct.ap-hop-paris.fr; Fréderic Lioté - fliote@vapop.ucsd.edu; Pierre Durieux - pierre.durieux@spim.jussieu.fr; Philippe Ravaud - philippe.ravaud@bch.aphp.fr

* Corresponding author
\end{abstract}

Published: 28 July 2009

BMC Health Services Research 2009, 9:128 doi:10.1 186/1472-6963-9-128
Received: 4 July 2008

Accepted: 28 July 2009

This article is available from: http://www.biomedcentral.com//472-6963/9//28

(C) 2009 Pham et al; licensee BioMed Central Ltd.

This is an Open Access article distributed under the terms of the Creative Commons Attribution License (http://creativecommons.org/licenses/by/2.0), which permits unrestricted use, distribution, and reproduction in any medium, provided the original work is properly cited.

\begin{abstract}
Background: Clinical vignettes have been used widely to compare quality of clinical care and to assess variation in practice, but the effect of different response formats has not been extensively evaluated. Our objective was to compare three clinical vignette-based survey response formats - open-ended questionnaire $(A)$, closed-ended (multiple-choice) questionnaire with deceptive response items mixed with correct items (B), and closed-ended questionnaire with only correct items (C) - in rheumatologists' pre-treatment assessment for tumor-necrosis-factor (TNF) blocker therapy.

Methods: Study design: Prospective randomized study. Setting: Rheumatologists attending the 2004 French Society of Rheumatology meeting. Physicians were given a vignette describing the history of a fictitious woman with active rheumatoid arthritis, who was a candidate for therapy with TNF blocking agents, and then were randomized to receive questionnaire $A, B$, or $C$, each containing the same four questions but with different response formats, that asked about their pretreatment assessment. Measurements: Long (recommended items) and short (mandatory items) checklists were developed for pretreatment assessment for TNF-blocker therapy, and scores were expressed on the basis of responses to questionnaires $A, B$, and $C$ as the percentage of respondents correctly choosing explicit items on these checklists. Statistical analysis: Comparison of the selected items using pairwise Chi-square tests with Bonferonni correction for variables with statistically significant differences.
\end{abstract}

Results: Data for all surveys distributed (II4 As, II8 Bs, and II8 Cs) were complete and available for analysis. The percentage of questionnaire $\mathrm{A}, \mathrm{B}$, and $\mathrm{C}$ respondents for whom data was correctly complete for the short checklist was $50.4 \%, 84.0 \%$ and $95.0 \%$, respectively, and was $0 \%, 5.0 \%$ and $5.9 \%$, respectively, for the long version. As an example, $65.8 \%, 85.7 \%$ and $95.8 \%$ of the respondents of $A, B$, and C questionnaires, respectively, correctly identified the need for tuberculin skin test $(p<0.000 \mathrm{I})$.

Conclusion: In evaluating clinical practice with use of a clinical vignette, a multiple-choice format rather than an open-ended format overestimates physician performance. The insertion of deceptive response items mixed with correct items in closed-ended (multiple-choice) questionnaire failed to avoid this overestimation. 


\section{Background}

Improvement of quality of clinical practice needs quality measurements. These measurements must be accurate, valid and feasible. The advantages and disadvantages of different methods of measuring the process of care, including both the competence of the clinician and what the clinician actually does, have been well described. Methods include chart extraction, standardized patients and clinical vignettes. Substantial inaccuracies in administrative data are common, which leads to expensive data extraction and difficulty in validating data [1-3]. Compared to standardized patients and chart extraction, clinical vignettes are an accurate, valid, feasible and inexpensive tool to measure quality of health care $[4,5]$. Thus, clinical vignettes have been used widely to compare quality of clinical care and to assess variation in practice across countries, health care systems, specialties or clinicians [6-11].

Vignette-based surveys for physicians feature open-ended questions rather than multiple-choice questions or checklists. In this way, physicians can give a personal response to each question, which ensures that the survey captures the full range of practice variation $[11,12]$. Open-ended questions avoid the "cueing" inherent in multiple-choice questions, which could overestimate real physician performance. However, the accuracy of close-ended questionnaires has been demonstrated in several domains: the format provides a significantly higher rate of accuracy than an open-ended format in terms of eyewitness confidence with the former format [13]. Close-ended questionnaires maximize questionnaire response rate and ensure questionnaire completeness [14].

Moreover, different formats yield different answers: in one study, a closed-ended questionnaire produced results reflecting higher willingness to pay for a health care intervention, with different justifications for those evaluations than did those from an open-ended one [15]. A public opinion survey with two different response modalities asked subjects about the most important problem facing the United States: respondents of the open-ended format most often complained about political leadership, whereas those of the close-ended format considered violence as most important [16].

From these data, we wanted to evaluate how clinical vignette-based surveys influence physician responses. Assuming that closed-ended (multiple-choice) questions for vignettes produce different responses than openended, leading to an overestimation of professional performance, we aimed to determine whether the influence of deceptive response items included in the closed-ended questionnaires result in a better assessment of professional performance.

\section{Methods}

We conducted a prospective randomized study aimed at comparing three response modalities for a vignette-based survey: open-ended questionnaire, closed-ended questionnaire (with only correct response items) and closedended questionnaire with deceptive response items mixed with correct items.

\section{Survey}

The survey was composed of two parts. The first part was short, identical in each questionnaire, and collected demographic characteristics and specialties of physicians. The second part was the clinical vignette.

\section{Vignette}

The vignette reported the history of a fictitious 50-year-old woman with active rheumatoid arthritis, a candidate for therapy with tumor necrosis factor (TNF) blocking agents. Physicians were asked to answer four questions about their pre-treatment assessment, considering that TNFblocking treatment was planned: 1) what specific data are you searching for in this patient's history? 2) What clinical data are you personally searching for during the physical examination? 3) Which biological, radiographic or other tests do you request? 4) What other preventive measures do you take? Physicians were given these questions in one of three questionnaire formats: open-ended questionnaire (questionnaire A) [see Additional file 1], closed-ended (multiple-choice) questionnaire with deceptive response items mixed with correct items $(\mathrm{n}=73$ ) (questionnaire $\mathrm{B}$ ) [see Additional file 2], closed-ended questionnaire with only correct items $(\mathrm{n}=35)$ (questionnaire $\mathrm{C})$ [see Additional file 3]. Deceptive and correct response items were created by following published international and national recommendations to help physicians care for patients under this treatment [17-21]. Three experts (XM, TP and FL) met to formulate correct and deceptive items. They based their work on the published international and national recommendations to help physicians care for patients under this treatment, to first determine the correct items, and then propose deceptive items. Each expert has elaborated 20 deceptive items, within 4 categories: patient's history, physical examination, biological, radiographic or other tests and other preventive measures. From the 53 elaborated items (duplicates were eliminated), only the more believable were kept, allowing to propose 38 deceptive items, which were mixed with the 35 correct items in questionnaire B.

\section{Scoring}

Responses to questionnaire A were coded for comparison to those of the other two questionnaires. For each item, the response was classified as "item correctly selected"; "item incorrectly selected"; "item correctly not selected"; "item incorrectly not selected." We classified each item 
according to three sources: an evidence-based literature search of clinical practice concerning TNF-blocking drug management, international and national guidelines, and a French clinical tool guide on use of TNF-blocking agents elaborated by an expert panel of academic and community physicians [22]. From these sources, we developed two checklists of items for pretreatment assessment for TNF-blocker therapy: a long version extracted from the French clinical tool guide on use of TNF-blocking agents [22], with detailed data on research into possible contraindications (Table 1), and a short version extracted from the same clinical tool guide and from the French

Table I: Long version of the checklist of correct items in pretreatment assessment for TNF-blocker therapy extracted from the French clinical tool guide [22]:

Question I: What specific data are you searching for in this patient's history?

History of primary tuberculosis infection or of visceral tuberculosis

History of vaccination with BCG (bacille Calmette-Guerin)

History of positive response to intradermal tuberculin testing

History of correct treatment for possible active tuberculosis

History of infection: cutaneous

History of infection: pulmonary

History of infection: urinary

History of infection: septicemia

History of infection: septic arthritis

History of neurologic disease

History of neoplasia or of hemopathy

Question 2: What clinical data are you personally searching for during the physical examination?

Lymphadenopathy

Neurologic abnormalities

Question 3: Which biological, radiolographic or other tests do you request?

Blood count

Serum protein electrophoresis

Liver function tests

Hepatitis C serology

HIV serology

Antinuclear antibodies

Chest x-ray

Question 4: What other preventive measures do you take?

Tuberculin skin test 
agency for health care recommendations with items mandatory in France (Table 2) [23].

\section{Questionnaire administration}

During the 2004 French Society of Rheumatology meeting, rheumatologists were asked to participate in a survey concerning pretreatment assessment in cases of therapy with TNF blockers, which aimed at detecting contraindications to treatment. The survey was conducted on behalf of the Club Rhumatismes et Inflammation (CRI), the division of the French Society of Rheumatology dedicated to musculosquelettal inflammatory diseases.

Until the targeted sample size was achieved, the survey distribution was randomized, with each physician receiving only one questionnaire format (A, B or C). Rheumatologists were blinded to the hypothesis. Particularly, they were unaware of the existence of different response modalities, of deceptive items in questionnaire $\mathrm{B}$, and that all items of questionnaire $\mathrm{C}$ were correct. Time to complete the survey was limited to fifteen minutes.

Four interviewers were responsible for encouraging participation in the survey, explaining the official nature of the survey, checking that all the questionnaires were correctly completed in the time allowed, and checking the randomization was achieved. Participation was voluntary, and physicians' responses were kept anonymous.

\section{Statistical analysis}

A chi-square test was used to compare the proportion of items selected or not in terms of the questionnaire format of each of the three questionnaires. A p $<0.05$ was considered statistically significant. Pairwise chi-square tests with Bonferonni correction (corrected significant probability of 0.017 ) were used to compare variables with statistically significant differences. Statistical analysis involved use of SAS Release 8.2 and Splus 6.2.
Sample size calculation: Three sets of 100 questionnaires - one set for each of the three questionnaires - were planned for the analysis. In fact, when considering pairwise comparisons for the response item "tuberculin skin test, " with a sample size of 100 in two groups, a two-group chi-square test with a 0.017 two-sided significance level would have $80 \%$ power to detect a difference between a $65 \%$ proportion in one group and a $85 \%$ proportion in the other group. Because we expected 15\% incomplete or non-analyzable questionnaires, we distributed 350 questionnaires.

\section{Results \\ Respondents}

Of 350 questionnaires dispensed (114 questionnaire As, 118 questionnaire Bs and 118 questionnaire Cs), all were completed, and all responses were eligible for further analysis. Table 3 displays demographic and specialty characteristics of physicians responding to the identical format part of the survey. Physicians were similar in terms of sex, practice duration and practice modalities. Questionnaire A respondents were younger than those of the other two questionnaires. Only two questions were asked about rheumatologists' experience with TNF-blocking drugs: $69.4 \%$ had already prescribed anti-TNF therapy and $43.1 \%$ had access to a checklist for screening potential contraindications in their department.

\section{Questionnaire responses}

Although we expected 15\% incomplete or non-analyzable questionnaires, we did not observe any missing data for open-ended or closed-ended questionnaires.

Significant differences depending on questionnaire format were found in reporting pre-treatment assessment. Compared with the two closed-ended questionnaires, the open-ended questionnaire gave lower reporting of items correctly selected and correctly not selected (Table 4).

Table 2: Short version of the checklist of correct items in pretreatment assessment for TNF-blocker therapy extracted from the French agency for health care recommendations (mandatory in France)[23]:

Question I: What specific data are you searching for in this patient's history?

History of tuberculosis

Question 2: What clinical data are you personally searching for during the physical examination?

None

Question 3: Which biological, radiographic or other tests do you request?

Chest x-ray

Question 4: What other preventive measures do you take?

Tuberculin skin test 
Table 3: Demographic characteristics and specialties of physicians completing questionnaires A, B and C.

\begin{tabular}{|c|c|c|c|c|}
\hline \multicolumn{2}{|c|}{ Physician characteristics } & $\begin{array}{l}\text { Questionnaire A } \\
\text { (open-ended) }\end{array}$ & $\begin{array}{c}\text { Questionnaire B } \\
\text { (closed-ended with deceptive } \\
\text { items) }\end{array}$ & $\begin{array}{l}\text { Questionnaire C } \\
\text { (closed-ended) }\end{array}$ \\
\hline \multicolumn{2}{|l|}{$\mathrm{N}$} & 114 & 118 & 118 \\
\hline \multicolumn{2}{|c|}{ Sex (\% female) } & 41.2 & 37.3 & 37.3 \\
\hline \multicolumn{2}{|c|}{ Age (mean $\pm S D)$} & $43.8 \pm 9.2$ & $46.4 \pm 8.8$ & $47.2 \pm 9.6$ \\
\hline \multicolumn{2}{|c|}{ Years practicing rheumatology (mean $\pm S D$ ) } & $17.8 \pm 8.6$ & $18.7 \pm 8.5$ & $19.4 \pm 8.9$ \\
\hline & Exclusive private practice (\%) & 35.0 & 32.8 & 31.1 \\
\hline \multirow[t]{2}{*}{ Practice } & $\begin{array}{l}\text { Both private and public } \\
\text { practice }(\%)\end{array}$ & 26.5 & 32.8 & 28.6 \\
\hline & Exclusive public practice (\%) & 38.5 & 34.4 & 40.3 \\
\hline \multicolumn{2}{|c|}{ Previously prescribed TNF-blocking drug (yes, \%) } & 64.9 & 68.6 & 73.9 \\
\hline \multicolumn{2}{|c|}{$\begin{array}{l}\text { Access to a checklist before TNF-blocker drug } \\
\text { prescription (yes, \%) }\end{array}$} & 46.6 & 44.5 & 51.9 \\
\hline
\end{tabular}

Questionnaire A: open-ended; Questionnaire B: closed-ended with deceptive items; Questionnaire C: closed-ended

In terms of global results, none of the questionnaire A respondents proposed response items of the long checklist, although $5.0 \%$ and $5.9 \%$ of questionnaire $\mathrm{B}$ and $\mathrm{C}$ respondents, respectively, correctly selected all items (Table 4).

For the A, B and C questionnaires, 50.4\%, 84.0\% and $95.0 \%$ respondents, respectively, correctly selected all mandatory response items of the short checklist. When focusing on response items within the short checklist, questionnaires $\mathrm{B}$ and $\mathrm{C}$ did not produce differences in responses to item "order chest X-rays" also difference was observed with open- and close-ended questionnaires ( $\mathrm{p}<$ 0.0001 ) (Table 4). In contrast, respondents to question- naires $\mathrm{A}, \mathrm{B}$, and $\mathrm{C}$ significantly differed in responses for another mandatory item, "obtaining a tuberculin skin test": $65.8 \%, 85.7 \%$ and $95.8 \%$ respondents, respectively, identified this item.

Rheumatologists completing the closed-ended questionnaire $\mathrm{B}$, with deceptive response items, more often chose these items, such as seeking advice of a systematic lung specialist $(26.1 \%)$ or determining blood sugar level (40.3\%). None of the questionnaire A respondents spontaneously proposed these items. Questionnaire B respondents showed a tendency for a lower percentage of correctly selected items than questionnaire $\mathrm{C}$ respondents. The open-ended format allowed for collecting qual-

Table 4: Percentage of physicians who correctly selected all the items of the short or long checklist for pretreatment assessment for TNF-blocker therapy and to specific items, by questionnaire A, B and C and pairwise chi-square comparison

\begin{tabular}{|c|c|c|c|c|c|c|c|}
\hline & Questionnaire A & Questionnaire B & Questionnaire C & $\begin{array}{l}A \text { and } B \text { comparison } \\
P \text {-value }\end{array}$ & $\begin{array}{c}\mathrm{A} \text { and } \mathrm{C} \\
\text { comparison } \\
\mathrm{P} \text {-value }\end{array}$ & $\begin{array}{c}\mathrm{B} \text { and } \mathrm{C} \\
\text { comparison } \\
\mathrm{P} \text {-value }\end{array}$ & $\begin{array}{c}\mathrm{A}, \mathrm{B} \text { and } \mathrm{C} \\
\text { comparison } \\
\mathrm{P} \text {-value }\end{array}$ \\
\hline Long version of checklist & 0.0 & 5.0 & 5.9 & 0.0293 & 0.0143 & 1.0000 & 0.0167 \\
\hline $\begin{array}{l}\text { Short version of } \\
\text { checklist }\end{array}$ & 50.4 & 84.0 & 95.0 & $<0.0001$ & $<0.0001$ & $<0.000$ I & 0.0060 \\
\hline $\begin{array}{l}\text { Chose item "chest X- } \\
\text { rays" }\end{array}$ & 84.6 & 96.6 & 98.3 & 0.0015 & 0.0002 & 0.6835 & $<0.0001$ \\
\hline $\begin{array}{l}\text { Chose item "tuberculin } \\
\text { skin test" }\end{array}$ & 65.8 & 85.7 & 95.8 & 0.0004 & $<0.0001$ & 0.0072 & $<0.0001$ \\
\hline
\end{tabular}

Questionnaire A: open-ended; Questionnaire B: closed-ended with deceptive items; Questionnaire C: closed-ended 
itative data on items that we did not propose in the closeended questionnaires, such as "give information to the patient on potential adverse effects" or "give information to the patient on monitoring these drugs."

\section{Discussion}

We compared three clinical vignette-based survey response formats: an open-ended questionnaire, a closedended (multiple-choice) questionnaire with cued correct items and a closed-ended questionnaire with deceptive items mixed with correct items. As expected, use of a closed-ended questionnaire with cued items overestimated physicians' performance as compared with an open-ended questionnaire, given that the latter is considered as the gold standard in assessing practice $[5,12,24]$. Also as expected, the open-ended questionnaire supplied more information on clinical practice than the closeended questionnaires; physicians were more willing to provide information to the patient. Although we included response items on examinations or tests, such as cutaneous examination, in the closed-ended questionnaires, none of the respondents of the open-ended questionnaire suggested such tests.

Our study focuses on the difficulty in evaluating the quality of physician performance for specific domains with open-ended questionnaires. Physicians may be more brief with open-ended formats and responses may be less accurate. Of the 114 questionnaire A respondents, 74.4\% responded with "tuberculosis" to the "other tests" question but gave no specific description of a test or what clinical examination they would do to evaluate this tuberculosis risk. In the closed-ended format, we assumed that including deceptive items would influence respondents' answers and lower the overestimation inherent in the closed-format survey. To our knowledge, this is the first time that deceptive items have been mixed with cued items in a close-ended questionnaire. Questionnaire B respondents indeed selected fewer correct items than did questionnaire $\mathrm{C}$ respondents. However, these results were very different from those obtained with the open-ended questionnaire (A), which are probably closer to reality.

The influence of framing questionnaire items remains crucial for clinical practice evaluation. This bias in response acquiescence has been reported from study of two versions of a training satisfaction questionnaire randomly distributed to medical residents; in one, half the items were stated positively and half negatively, and in the other, all items were stated positively. Results showed a significant effect of positive versus negative framing [25].

\section{Conclusion}

In conclusion, even if closed-ended questionnaires may provide more accurate data in clinical practice evaluation, general open-question format has value in such evaluation. Strategies for generating quantitative and qualitative data from open-ended questionnaires, associated or not with closed-ended questionnaires, facilitating survey analysis, are very likely interesting to develop to improve physician performance evaluation [25].

\section{Competing interests}

This study was support by an educational grant from Wyeth Pharmaceuticals. The pharmaceutical company has paid for the 3-day employment of the 4 Ipsos interviewers. Ipsos is an independent company focused on survey-based research. The authors did not receive money from the pharmaceutical company.

\section{Authors' contributions}

TP participated in the design of the study, carried out the survey, participated in the elaboration of the clinical vignettes and drafted the manuscript. CS performed the statistical analysis. XM and FL participated in the elaboration of the clinical vignettes and especially the formulation of the correct and deceptive items. PD participated in the design of the study and its coordination. PR conceived of the study, and participated in its design and coordination. All authors read and approved the final manuscript.

\section{Additional material}

\section{Additional file 1}

Questionnaire A. Vignette reporting history of a fictitious 50-year-old woman with active rheumatoid arthritis, candidate for therapy with tumor necrosis factor (TNF) blocking agents, with an open-ended questionnaire about pre-treatment assessment.

Click here for file

[http://www.biomedcentral.com/content/supplementary/14726963-9-128-S1.pdf]

\section{Additional file 2}

Questionnaire B. Vignette reporting history of a fictitious 50-year-old woman with active rheumatoid arthritis, candidate for therapy with tumor necrosis factor (TNF) blocking agents, with a closed-ended (multiple-choice) questionnaire about pre-treatment assessment containing deceptive response items mixed with correct items.

Click here for file

[http://www.biomedcentral.com/content/supplementary/14726963-9-128-S2.pdf]

\section{Additional file 3}

Questionnaire C. Vignette reporting history of a fictitious 50-year-old woman with active rheumatoid arthritis, candidate for therapy with tumor necrosis factor (TNF) blocking agents, with a closed-ended (multiple-choice) questionnaire about pre-treatment assessment containing only correct items.

Click here for file

[http://www.biomedcentral.com/content/supplementary/14726963-9-128-S3.pdf] 


\section{Acknowledgements}

The authors thank Laura Heraty for her thoughtful review of this manuscript before submission.

\section{References}

I. Peabody JW, Luck J, Jain S, Bertenthal D, Glassman P: Assessing the accuracy of administrative data in health information systems. Med Care 2004, 42(I I): I066-72.

2. Lloyd SS, Rissing JP: Physician and coding errors in patient records. JAMA 1985, 254(I 0): | 330-6

3. Green J, Wintfeld N: How accurate are hospital discharge data for evaluating effectiveness of care? Med Care 1993, 3 I (8):7|9-3I.

4. Peabody JW, Luck J, Glassman P, Jain S, Hansen J, Spell M, et al.: Measuring the quality of physician practice by using clinical vignettes: a prospective validation study. Ann Intern Med 2004, I 4 I ( I 0):77|-80.

5. Peabody JW, Luck J, Glassman P, Dresselhaus TR, Lee M: Comparison of vignettes, standardized patients, and chart abstraction: a prospective validation study of 3 methods for measuring quality. JAMA 2000, 283(13): I7I5-22.

6. Peabody JW, Nordyke RJ, Tozija F, Luck J, Muñoz JA, Sunderland A, et al:: Quality of care and its impact on population health: a cross-sectional study from Macedonia. Soc Sci Med 2006, 62(9):2216-24.

7. Peabody JW, Tozija F, Muñoz JA, Nordyke RJ, Luck J: Using vignettes to compare the quality of clinical care variation in economically divergent countries. Health Serv Res 2004, 39(6 Pt 2): $195 \mid-70$.

8. Peabody JW, Liu A: A cross-national comparison of the quality of clinical care using vignettes. Health Policy Plan 2007, 22(5):294-302.

9. Sriram TG, Chandrashekar CR, Isaac MK, Srinivasa Murthy R, Kishore Kumar KV, Moily S, et al: Development of case vignettes to assess the mental health training of primary care medical officers. Acta Psychiatr Scand 1990, 82(2): I74-7.

10. Landon BE, Reschovsky J, Reed M, D B: Personal, organizational, and market level influences on physicians' practice patterns: results of a national survey of primary care physicians. Med Care 200I, 39(8):889-905.

II. Veloski J, Tai S, Evans AS, Nash DB: Clinical vignette-based surveys: a tool for assessing physician practice variation. $\mathrm{Am} J$ Med Qual 2005, 20(3): I51-7.

12. Sandvik $\mathrm{H}$ : Criterion validity of responses to patient vignettes: an analysis based on management of female urinary incontinence. Fam Med 1995, 27(6):388-92.

13. Venter A, Louw DA: The effect of confidence and method of questioning on eyewitness testimony. Med Law 2005, 24(2):369-89.

14. Griffiths LE, Cook DJ, Guyatt GH, Charles CA: Comparison of open and closed questionnaire formats in obtaining demographic information from Canadian general internists. J Clin Epidemiol 1999, 52(10):997-1005.

15. Frew EJ, Whynes DK, Wolstenholme JL: Eliciting willingness to pay: comparing closed-ended with open-ended and payment scale format. Med Decis Making 2003, 23:I50-I59.

16. Schuman $\mathrm{H}$, Presser $\mathrm{S}$ : Questions and answers in attitude surveys: experiments on question form, wording, and context. New York: Academic press 198I.

17. Emery P, Reginster JY, Appelboom T, Breedveld FC, Edelmann E, Kekow J, et al.: WHO Collaborating Centre consensus meeting on anti-cytokine therapy in rheumatoid arthritis. Rheumatology (Oxford) 2001, 40(6):699-702.

18. Ledingham J, Deighton C: Update on the British Society for Rheumatology guidelines for prescribing TNFalpha blockers in adults with rheumatoid arthritis (update of previous guidelines of April 200I). Rheumatology (Oxford) 2005, 44(2): I57-63.

19. Pham T, Guillemin F, Claudepierre P, Luc M, Miceli-Richard C, Fautrel $B$, et al.: TNFalpha antagonist therapy in ankylosing spondylitis and psoriatic arthritis: recommendations of the French Society for Rheumatology. Joint Bone Spine 2006, 73(5):547-53.

20. Fautrel B, Constantin A, Morel J, Vittecoq O, Cantagrel A, Combe B, et al.: Recommendations of the French Society for Rheuma- tology. TNFalpha antagonist therapy in rheumatoid arthritis. Joint Bone Spine 2006, 73(4):433-4I.

21. BTS recommendations for assessing risk and for managing Mycobacterium tuberculosis infection and disease in patients due to start anti-TNF-alpha treatment. Thorax 2005 , 60(10):800-5.

22. Pham T, Claudepierre P, Deprez X, Fautrel B, Goupille P, Hilliquin P, et al.: Anti-TNF alpha therapy and safety monitoring. Clinical tool guide elaborated by the Club Rhumatismes et Inflammations (CRI), section of the French Society of Rheumatology (Societe Francaise de Rhumatologie, SFR). Joint Bone Spine 2005, 72(Suppl I):SI-58.

23. AFSSAPS: Recommandations nationales. Prevention et prise en charge des tuberculoses survenant sous anti-TNF 2005 [http://www.afss aps.fr/content/download//2022//43647/version/2/file/reco.pdf].

24. Veloski J, Rabinowitz HK, Robeson MR, Young PR: Patients don't present with five choices: an alternative to multiple-choice tests in assessing physicians' competence. Academic Medicine 1999, 74(5):539-46.

25. O'Cathain A, Thomas KJ: "Any other comments?" Open questions on questionnaires - $\mathbf{a}$ bane or a bonus to research? $B M C$ Med Res Methodol 2004, 4:25.

\section{Pre-publication history}

The pre-publication history for this paper can be accessed here:

http://www.biomedcentral.com/1472-6963/9/128/pre pub
Publish with Bio Med Central and every scientist can read your work free of charge

"BioMed Central will be the most significant development for disseminating the results of biomedical research in our lifetime. "

Sir Paul Nurse, Cancer Research UK

Your research papers will be:

- available free of charge to the entire biomedical community

- peer reviewed and published immediately upon acceptance

- cited in PubMed and archived on PubMed Central

- yours - you keep the copyright 